\title{
A novel peptide (GXI) homing to gastric cancer vasculature inhibits angiogenesis and cooperates with TNF alpha in anti-tumor therapy Bei Chen ${ }^{\dagger 1}$, Shanshan Cao ${ }^{\dagger 1}$, Yingqi Zhang ${ }^{2}$, Xin Wang ${ }^{1}$, Jie Liu ${ }^{1}$, Xiaoli Hui ${ }^{1}$, Yi Wan², Wenqi Du¹, Li Wang1, Kaichun ${ }^{1}{ }^{*}{ }^{1}$ and Daiming Fan ${ }^{1}$
}

\author{
Address: ${ }^{1}$ State Key Laboratory of Cancer Biology and Xijing Hospital of Digestive Diseases, the Fourth Military Medical University, Xi'an, Shaanxi, \\ PR China and ${ }^{2}$ State Key Laboratory of Cancer Biology and Biotechnology Centre, the Fourth Military Medical University, Xi'an, Shaanxi, PR China \\ Email: Bei Chen - bzcheese@hotmail.com; Shanshan Cao - caoshanshan80@yahoo.com.cn; Yingqi Zhang - zhangyq@fmmu.edu.cn; \\ Xin Wang - wangx@fmmu.edu.cn; Jie Liu - jieliu@fmmu.edu.cn; Xiaoli Hui - hxlljt@126.com; Yi Wan - wany@yahoo.com.cn; \\ Wenqi Du -dwq0307@fmmu.edu.cn; Li Wang - xiaoyuan@fmmu.edu.cn; KaichunWu* - kaicwu@fmmu.edu.cn; \\ Daiming Fan - fandaim@fmmu.edu.cn \\ * Corresponding author †Equal contributors
}

Published: 9 September 2009

BMC Cell Biology 2009, 10:63 doi:10.1186/147|-2121-10-63
Received: 4 March 2009

Accepted: 9 September 2009

This article is available from: http://www.biomedcentral.com/I47I-2/2I//0/63

(C) 2009 Chen et al; licensee BioMed Central Ltd.

This is an Open Access article distributed under the terms of the Creative Commons Attribution License (http://creativecommons.org/licenses/by/2.0), which permits unrestricted use, distribution, and reproduction in any medium, provided the original work is properly cited.

\begin{abstract}
Background: The discovery of the importance of angiogenesis in tumor growth has emphasized the need to find specific vascular targets for tumor-targeted therapies. Previously, using phage display technology, we identified the peptide GXI as having the ability to target the gastric cancer vasculature. The present study investigated the bioactivities of GXI, as well as its potential ability to cooperate with recombinant mutant human tumor necrosis factor alpha ( $r \mathrm{mhTNF} \alpha$ ), in gastric cancer therapy.

Results: Tetrazolium salt (MTT) assay showed that GXI could inhibit cell proliferation of both human umbilical vein endothelial cells (HUVEC) (44\%) and HUVEC with tumor endothelium characteristics, generated by culturing in tumor-conditioned medium (co-HUVEC) (62\%). Flow-cytometry (FCM) and western blot assays showed that GXI increased the rate of apoptosis from II\% to $31 \%(p<0.0 \mathrm{I})$ by upregulating caspase 3 expression level. A chorioallantoic membrane assay indicated that GXI could suppress neovascularization in vivo, with the microvessel count decreasing from $2 \mathrm{I}$ to $\mathrm{II}(p<0.05)$. When GXI was fused to rmhTNF $\alpha, G X I-r m h T N F \alpha$ selectively concentrated in the gastric cancer vasculature, as shown by enzyme-linked immunosorbent assay, immunofluorescence and emission-computed tomography. In vitro MTT and FCM assays showed that, compared to rmhTNF $\alpha$ alone, GXI-rmhTNF $\alpha$ was more effective at suppressing co-HUVEC proliferation $(45 \%$ vs. $61 \%, p<0.05)$ and inducing apoptosis (II\% vs. $23 \%, p<0.05$ ). In a tumor formation test, GXI-rmhTNF $\alpha$ more effectively inhibited tumor growth than rmhTNF $\alpha$ (tumor volume: $271 \mathrm{~mm}^{3}$ vs. $134 \mathrm{~mm}^{3}, p<0.05$ ), with less systemic toxicity as measured by body weight $(20.57 \mathrm{~g}$ vs. $19.30 \mathrm{~g}, p<0.05)$. These therapeutic effects may be mediated by selectively enhanced tumor vascular permeability, as indicated by Evan's blue assay.

Conclusion: GXI had both homing activity and the ability to inhibit vascular endothelial cell proliferation in vitro and neovascularization in vivo. Furthermore, when GXI was conjugated to rmhTNF $\alpha$, the fusion protein was selectively delivered to targeted tumor sites, significantly improving the anti-tumor activity of rmhTNF $\alpha$ and decreasing systemic toxicity. These results demonstrate the potential of GXI as a homing peptide in vascular targeted therapy for gastric cancer.
\end{abstract}




\section{Background}

Ever since the essential role of angiogenesis in tumor formation and metastasis was proposed by Folkman in 1971, increasing attention has been paid to vascular targeted therapy [1-3]. The vasculature is an attractive target because vascular endothelial cells are more genetically stable than tumor parenchymal cells and less likely to acquire drug resistance, and vascular targets on endothelial cells are readily accessible to systemically delivered agents [4-6]. Based on these advantages, efforts have focused on identifying specific molecules expressed on the surface of tumor vascular endothelial and perivascular cells $[7,8]$. Finding such tumor vascular targets may help make anticancer drugs more selective, through their targeted delivery, thus providing higher therapeutic efficiency while simultaneously decreasing systemic toxicity.

With this goal, we previously used in vivo screening of a phage-displayed peptide library to identify a cyclic 7-mer peptide, CGNSNPKSC, called GX1, which binds specifically to the human gastric cancer vasculature [9]. Immunohistochemical staining, enzyme-linked immunosorbent assay (ELISA), and immunofluorescence confirmed the targeting activity of GX1 peptide, indicating that GX1 might be used as a novel vascular marker for human gastric cancer [10]. The potential bioactivities that might accompany the targeting function of GX1, and how it might be combined with other agents for antitumor therapy, are investigated here. We conducted a series of tests to determine the effects of GX1 on vascular endothelial cells, and on tumor angiogenesis and growth. In addition, we fused GX1 to recombinant mutant human tumor necrosis factor ( $\mathrm{rmhTNF} \alpha$ ), a variant of the TNF $\alpha$ cytokine that is well known for its potent antitumor activity and is less toxic than TNF $\alpha[11,12]$, to see if the fusion protein could achieve synergistic therapeutic efficacy. These studies provide important preclinical evidence for the use of GX1 in targeted antitumor therapy.

\section{Results}

\section{GXI inhibits endothelial cell proliferation in vitro by inducing apoptosis}

GX1 was tested for its ability to inhibit both endothelial cells and tumor cell proliferation by the tetrazolium salt (MTT) assay. The results showed that GX1 could reproducibly suppress, in dose-dependent manner, the proliferation of human umbilical vein endothelial cells (HUVEC) and HUVEC with tumor endothelial cell characteristics (co-HUVEC), generated by culturing the cells in tumorconditioned medium [13]. Differences in the relative cell number between cells treated with GX1 and the control peptide (Pep2) were significant at concentrations of 10 , $25,50,75$ and $100 \mu \mathrm{M}$ for co-HUVEC $(p<0.01)$ (Figure $1 \mathrm{~A})$, and were significant at 75 and $100 \mu \mathrm{M}$ for HUVEC ( $p$ $<0.05$ ) (Figure 1B). In addition, GX1-induced inhibitory effects were more obvious in co-HUVEC than in the non- tumor conditioned HUVEC (Figure 1C). In contrast, no such differences were detectable in gastric adenocarcinoma SGC7901 cells (Figure 1D), further demonstrating the selectivity of GX1.

Subsequently using flow-cytometry (FCM), it was found that GX1 (50 $\mu \mathrm{M})$, but not Pep2 $(50 \mu \mathrm{M})$, induced apoptosis in co-HUVEC compared to the phosphate-buffer saline (PBS) control (apoptosis rate: $31.2 \%$ vs. $11.4 \%, p<$ 0.01 ) (Figure 1E). However, assessment of cell cycle distribution by FCM showed no significant difference between the test and control groups. These results indicated that inhibition of vascular endothelial cell proliferation by GX1 was, at least in part, through induction of apoptosis. We further detected the expression level of the apoptosis related molecule caspase 3 by western blot. As shown in Figure 1F, the expression of cleaved caspase 3 was up-regulated in GX1 $(50 \mu \mathrm{M})$ treated co-HUVEC. In contrast, no changes were detected in Pep2 $(50 \mu \mathrm{M})$ or PBS treated cells. In brief, GX1 appeared to induce apoptosis of coHUVEC by up-regulating the expression of caspase 3 .

\section{GXI inhibits angiogenesis in vivo by a chorioallantoic membrane (CAM) assay}

Since GX1 could repress vascular endothelial cell proliferation in vitro, we carried out CAM assays to see if the peptide could inhibit angiogenesis in vivo. Disruption of angiogenesis was observed in GX1-treated chicken embryos, with attenuated and tortuous microvessels in the CAM and fewer angiogenic vessels contacting the disk, when compared to the PBS control group. No significant differences existed between the Pep 2 and PBS control groups, with both showing well-developed and leaf veinlike vascular nets (Figure 2).

\section{GXI conjugated to rmhTNF $\alpha$ concentrates in gastric cancer}

In addition to proapoptotic and anti-angiogenic activity, GX1 was also assessed for its ability to act as a targeting delivery vector in combination therapy for gastric adenocarcinoma. GX1 was fused to rmhTNFa as previously reported [14] and its tumor-targeted distribution was investigated. ELISA was used to analyze the amount of GX1-rmhTNFa in tumor and non-tumor tissues, and the results showed that GX1-rmhTNF $\alpha$ accumulated in tumor tissues over time. The radioactivity of GX1-rmhTNF $\alpha$ relative to rmhTNF (GX1-rmhTNF $\alpha /$ rmhTNF $\alpha$ rate) significantly increased in tumor tissue from 0.95 at $0.5 \mathrm{~h}$ to 3.84 at $2 \mathrm{~h}(p<0.01)$. In contrast, this ratio decreased in liver within $2 \mathrm{~h}$ after administration of the agent $(p<0.05)$, and no evident trend was observed in other major organs (Figure 3).

We took planar scintigrams of tumor-bearing mice injected with ${ }^{9} \mathrm{Tc}^{\mathrm{m}}$-GX1-rmhTNF $\alpha$, to further confirm the in vivo tumor-targeting. Compared to ${ }^{9}{ }^{9} \mathrm{Tc}^{\mathrm{m}}$-rmhTNFa 

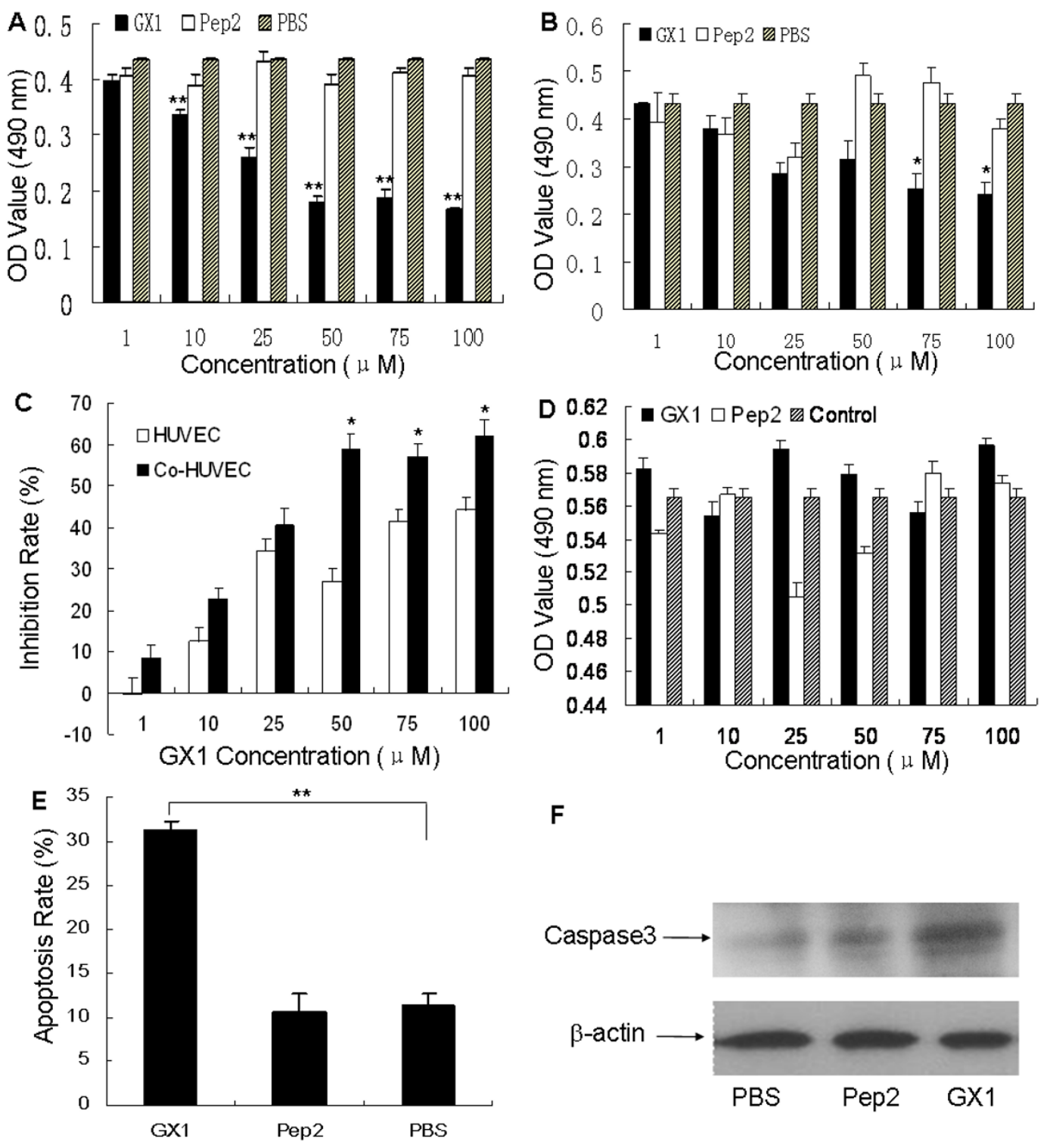

$\mathbf{F}$
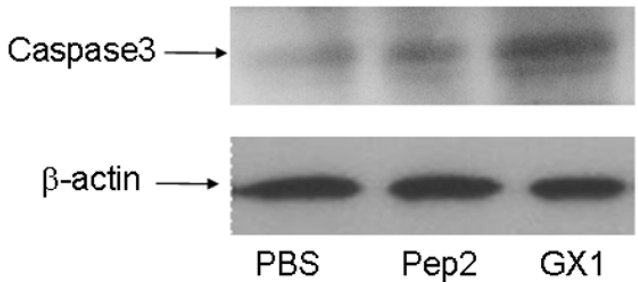

Figure I

GXI inhibits cell proliferation of both co-HUVEC and HUVEC through induction of apoptosis. GXI was shown by MTT assay to suppress the proliferation of co-HUVEC (A) and HUVEC (B) in a dose-dependent manner. (C) GXI had a greater inhibitory effect on co-HUVEC than HUVEC. (D) GXI had no obvious effect on gastric adenocarcinoma SGC790I cells. (E) GXI at $50 \mu \mathrm{M}$ significantly enhanced apoptosis of co-HUVEC over PBS treatment. The results are reported as mean $\pm \mathrm{SD}$ of three independent experiments. Bars, SD. $* p<0.05$, $* * p<0.0 \mathrm{I}$. (F) GXI at $50 \mu \mathrm{M}$ remarkably up-regulated caspase 3 expression level.

(Figure 4B, D), the radioactivity in tumor tissue was much higher in the ${ }^{99} \mathrm{Tc}^{\mathrm{m}}-\mathrm{GX} 1-\mathrm{rmhTNF} \alpha$ group (Figure 4A, C). The tumor/muscle radioactivity ratios of ${ }^{9}{ }^{9} \mathrm{Tc}^{\mathrm{m}}-\mathrm{GX} 1-$ rmhTNF $\alpha$ and ${ }^{99}{ }^{9} c^{m}$-rmhTNF $\alpha$ were 8.24 and 1.42 , respectively, at $18 \mathrm{~h}(p<0.05)$. Simultaneously, immunofluorescence was used to detect the specific location of

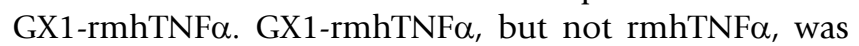
found to co-localize with CD31 which was used as a positive control in tumor vasculature (Figure 4E-G). Collec- tively, these results suggest that the fusion protein acquired the ability to target tumor vessels and may lead to more selective drug delivery to tumors.

\section{GXI-rmhTNF $\alpha$ inhibits co-HUVEC proliferation in vitro by inducing apoptosis}

The MTT assay was used to detect the effects of GX1-rmhTNF $\alpha$ on endothelial cell proliferation, and showed that the fusion protein was significantly better at inhibiting co- 


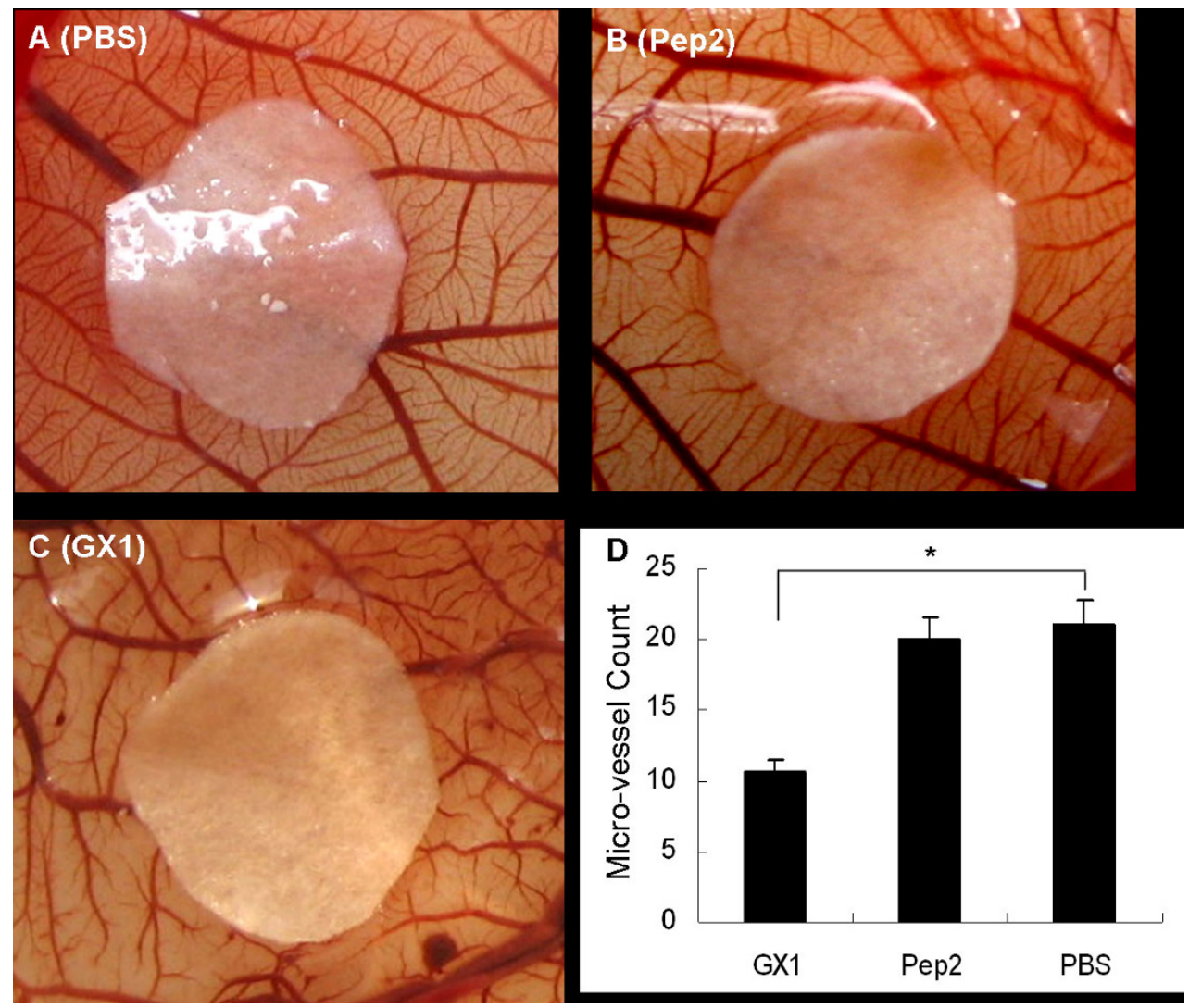

\section{Figure 2}

GXI inhibits angiogenesis in CAM assay. (A-C) GXI at $20 \mu \mathrm{g}(50 \mu \mathrm{M})$ hampered neovascularization of fertilized eggs. Attenuated and tortuous microvessels are shown in the CAM, with fewer angiogenic vessels contacting the filter disks. (D) Number of microvessels contacting the disks. Bars, SD. $* p<0.05$.

HUVEC proliferation than $\operatorname{rmhTNF} \alpha$, with inhibition rates of $61 \%$ vs. $45 \%$ at $10 \mu \mathrm{M}(p<0.05)$ (Figure $5 \mathrm{~A})$.

To address whether the decrease in cell number was due to apoptosis induced by GX1-rmhTNF $\alpha$, FCM was used to determine the apoptosis rate in co-HUVEC. The results showed that the apoptosis rates induced by $10 \mu \mathrm{M}$ GX1rmhTNF $\alpha$ or rmhTNF $\alpha$ were $23.4 \%$ and $11.2 \%$ respectively $(p<0.01)$ (Figure 5B). In contrast, no significant differences in cell cycle distribution were detected between the test and control groups. These results indicated that inhibition of vascular endothelial cells by GX1-rmhTNF $\alpha$ might be partly caused by induction of apoptosis.

\section{Effects of GXI-rmhTNF $\alpha$ on tumor growth in vivo}

Subsequently, using an in vivo tumor formation test, GX1rmhTNF $\alpha$ was assayed for its effects on tumor growth. Nude mice bearing human gastric adenocarcinoma xenografts were injected intravenously on alternate days with GX1-rmhTNF $\alpha(0.5 \mathrm{mg} / \mathrm{kg}), \operatorname{rmhTNF} \alpha(0.5 \mathrm{mg} / \mathrm{kg})$, GX1 $(0.25 \mathrm{mg} / \mathrm{kg}$ to account for its lower molecular weight) or normal saline (NS). Mouse body weight, which is used as a major indicator of TNF toxicity $[11,15]$, and tumor mass volumes were assessed over time. Tumor growth was significantly delayed by GX1-rmhTNF $\alpha$ treatment, and the average tumor volume of the GX1-rmhT$\mathrm{NF} \alpha$ group was much smaller than that of the rmhTNF $\alpha$ group (134.33 $\mathrm{mm}^{3}$ vs. $\left.271.50 \mathrm{~mm}^{3}, p<0.05\right)$ (Figure $6 \mathrm{~A})$. In addition, at the end of the test, mice treated with GX1-rmhTNF $\alpha$ had a higher average body weight than those treated with rmhTNF $\alpha(20.57 \mathrm{~g}$ vs. $19.30 \mathrm{~g}, p<0.05)$ (Figure 6B), suggesting that the fusion protein had less systemic toxicity than rmhTNF $\alpha$ alone.

Since TNF $\alpha$ is known to alter vascular barrier function, we performed Evan's blue assay to assess the effect of GX1rmhTNF $\alpha$ on tumor perfusion. Compared to rmhTNF $\alpha$ treated mice, the GX1-rmhTNF $\alpha$ treated group showed a greater leakage of Evan's blue dye in the tumor parenchyma. Differences were statistically significant at $0.5 \mathrm{mg} /$ $\mathrm{kg}(0.113$ vs. $0.073, p<0.05)$ (Figure $6 \mathrm{C})$. We therefore hypothesize that the GX1-rmhTNF $\alpha$ fusion protein selectively increases tumor vascular permeability and leads to higher local drug levels, which may play an important part in the antitumor mechanism of GX1-rmhTNFa. 


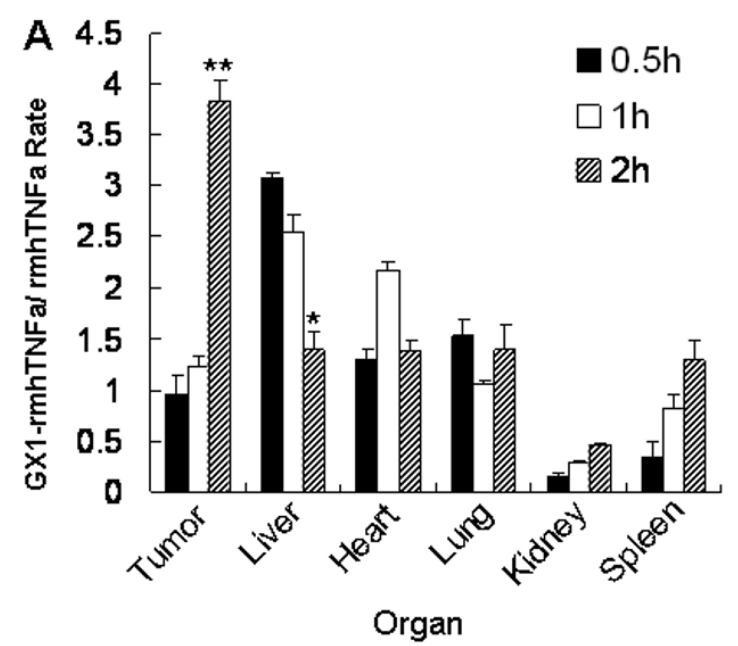

Figure 3

Distribution of GXI-rmhTNF $\alpha$ in various organs. GXI-rmhTNF $\alpha$ accumulated in tumor tissues over time and was gradually cleared from the liver. GXI-rmhTNF $\alpha / r m h T$ $\mathrm{NF} \alpha$ rate $=$ radioactivity of $\mathrm{GXI}-\mathrm{rmhTNF} \alpha$ relative to $\mathrm{rmhT}$ NF $\alpha$. Bars, SD. $*_{p}<0.05, *^{*} p<0.0 \mathrm{I}$.

\section{Discussion}

To improve therapeutic indices and decrease systemic toxicity, more specific and selective anticancer agents that can discriminate between tumor and nonmalignant cells are urgently needed, along with the development of antitumor radiochemotherapy [16-18]. The discovery that angiogenesis plays a crucial role in tumor formation, and that vascular targeting approaches exhibit the advantages of easy accessibility and lower incidence of drug resistance, provides a possible path to creating these new anticancer agents $[19,20]$. Several studies have pursued this strategy, including the application of phage display technology to pan for peptides that bind specifically to defined tissue targets $[8,21]$. Using this technique, several homing peptides have been identified, including RGD, NGR and F3, and many have showed promising results for imaging diagnosis and treatment of various tumors in preclinical or clinical investigations [22-25]. Furthermore, some of these peptides have been conjugated to bioactive agents, including drugs, cytokines, procoagulant factors, photosensitizers and radionuclides, and have been included in antineoplastic therapies. Initial results of these studies showed more selective and targeted drug delivery and fewer side effects $[7,21,26,27]$. However, to date, no such peptide has been identified that targets human gastric cancer.

Previously, we used in vivo screening of a phage displayed peptide library to identify GX1, a cyclic 7-mer peptide CGNSNPKSC that binds specifically to the human gastric cancer vasculature [9]. Autoradiography on different cell lines confirmed the targeting activity of GX1 toward the gastric cancer vascular endothelium, by showing that the binding affinity of GX1 was significantly higher in HUVEC cultured in tumor-conditioned medium than in HUVEC cultured in non-conditioned medium. No specific binding was observed in the human gastric carcinoma cell line SGC7901 or in the immortalized gastric epithelial cell line GES cells [28]. Furthermore, immunohistochemical staining and immunofluorescence showed positive staining for GX1 in the vascular endothelium of human gastric adenocarcinoma, but not in heart, liver, muscle, spleen or normal gastric tissues [10,28]. In another study, using single photon emission computed tomography (SPECT), GX1 labelled with ${ }^{99} \mathrm{Tc}^{\mathrm{m}} \mathrm{O}_{4}{ }^{-}{ }^{99}{ }^{9} \mathrm{Tc}^{\mathrm{m}}$ -GX1) was observed to concentrate in tumor xenografts in nude mice [28]. Collectively, these results indicate that GX1 is a novel vascular marker of human gastric cancer, and may lead to a new way of imaging diagnosis and targeted gastric cancer therapy.

Since GX1 selectively targeted the vascular endothelium of gastric cancer, we investigated whether it had specific effects on tumor angiogenesis and growth. In this study, in addition to targeting, GX1 showed bioactivity by both MTT and CAM assay, inhibiting vascular endothelial cell proliferation and hampering neovascularization. To probe into the possible mechanisms of these effects, the cell cycle distribution, cell apoptosis and the expression level of apoptosis related molecule caspase 3 were detected by FCM and western blot assays. Inhibition of vascular endothelial cell proliferation by GX1 was observed, at least in part, to be through the up-regulation of caspase 3 expression and the induction of apoptosis. Further tests including RT-PCR and gene microarray are underway to investigate the precise mechanisms.

In vitro analysis showed that HUVEC cultured in tumorconditioned media partially acquire the characteristics of tumor vascular endothelial cells, such as enhanced tubule formation, cell proliferation, and migration [13,29]. Furthermore, some proteins like vascular endothelial growth factor receptor and the integrin $\alpha v \beta 3$ may be up-regulated in co-HUVEC, as is the case for other cancer endothelia $[6,30]$. These findings lead us to the hypothesis that GX1 receptors are up-regulated in co-HUVEC, reflecting the case in tumor vessels, and that more receptors may lead to greater selective affinity and stronger anticancer effects. This hypothesis is consistent with the MTT assay results, in which GX1 showed more significant inhibitory effects on co-HUVEC than on the parental HUVEC culture that was not exposed to tumor-conditioned medium.

To assess the possibility of using GX1 as a targeted delivery vector in combination with another antitumor molecule 


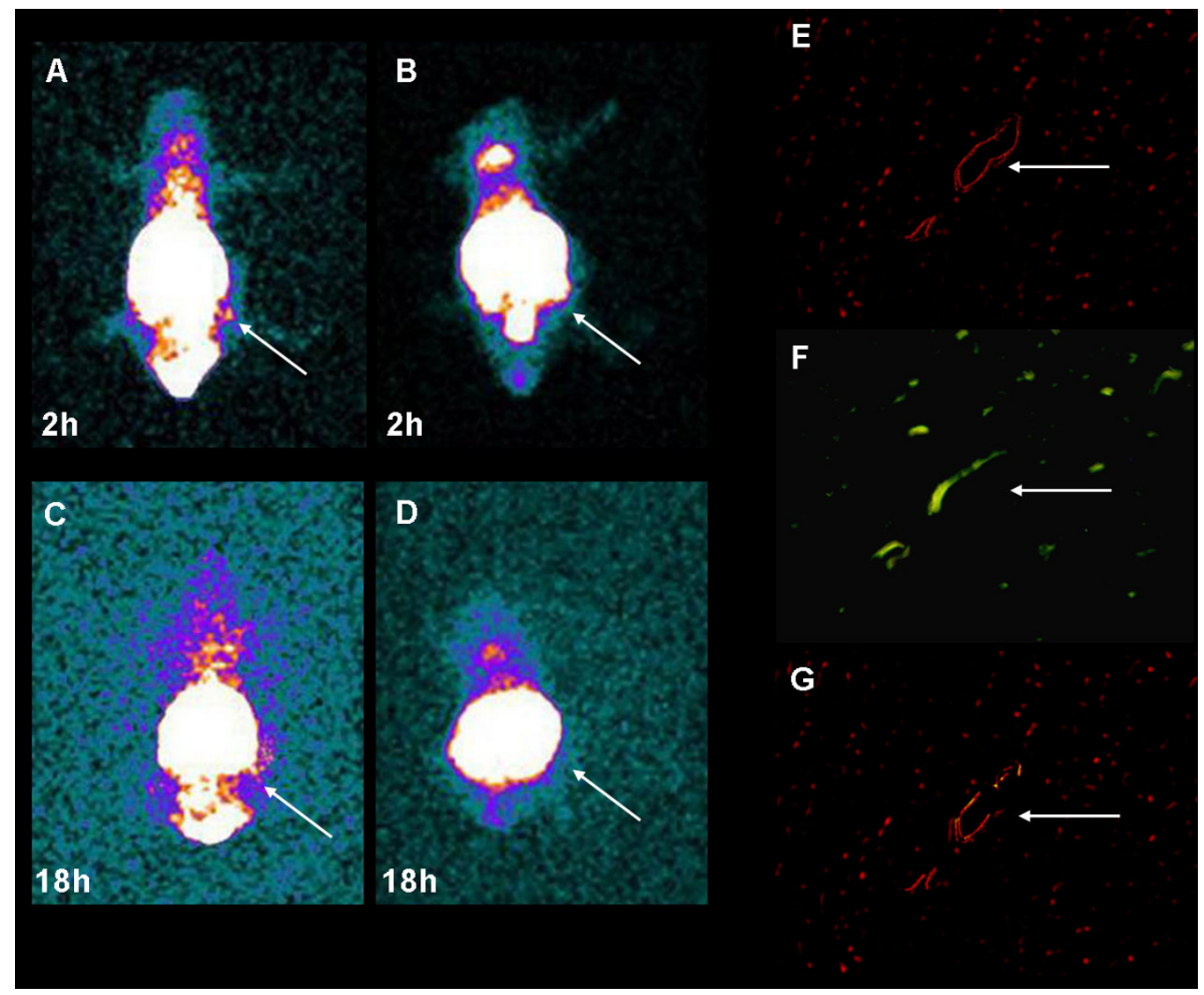

Figure 4

GXI-rmhTNF $\alpha$ selectively concentrates at gastric cancer cells. ${ }^{99} \mathrm{Tc} \mathrm{c}_{-} \mathrm{GXI}-\mathrm{rmhTNF} \alpha$ remained in tumor tissue from $2 \mathrm{~h}$ to $18 \mathrm{~h}$ after injection (A, C), while no such accumulation was seen in the ${ }^{99} \mathrm{Tc}^{\mathrm{m}}$-rmhTNF $\alpha$ group (B, D). Tumors are indicated by arrows. (E) Positive staining of CD3I in tumor vasculature (200x). (F) FITC-labeled GXI-rmhTNF $\alpha$ bound specifically to tumor vasculature (200x). (G) GXI-rmhTNF $\alpha$ colocalized with CD3I in tumor vasculature (200x). Arrow indicates a positively stained microvessel.

for treatment of gastric cancer, GX1 was conjugated to rmhTNF $\alpha$. TNF $\alpha$ is a well-known, antitumor cytokine whose clinical application is hampered by severe systemic toxicity $[12,15]$. The novel mutant cytokine rmhTNF $\alpha$ shows higher antitumor efficacy and has been approved for clinical use in China [12]. Our data showed that after fusion to GX1, rmhTNF $\alpha$ was selectively delivered to target tumor vasculature sites. Most important, GX1-rmhTNF $\alpha$ delayed tumor growth in vivo, with less loss of body weight compared to rmhTNF $\alpha$ alone (Figure 6A, B). These results indicated that more targeted and efficient antitumor activity might be achieved by combining GX1 with other anti-tumor agents (e.g. rmhTNF $\alpha$ ), for a significant reduction in systemic toxicity.

Despite the encouraging results, some questions are still open, such as what the receptor is for GX1 on vascular endothelial cells, and how ligand-receptor interaction interferes with tumor angiogenesis. Further studies are underway to answer these questions, and several candidate receptor molecules have been obtained. Identification of the GX1 receptor will be a great help in understanding the mechanism of GX1 and will accelerate the development of clinical applications for GX1 in diagnosis and targeted treatment of gastric cancer.

\section{Conclusion}

In conclusion, the data presented here, taken together with previously published results, demonstrate that GX1 is a novel vascular marker of human gastric cancer. For the first time GX1 is shown to have properties other than homing, including proapoptotic effects on vascular endothelial cells, and in vivo inhibition of neovascularization. Furthermore, when conjugated to rmhTNF $\alpha$, GX1 selectively delivered the fusion protein to target tumor sites, leading to higher antitumor efficiency with less systemic toxicity. These findings demonstrate great potential for developing GX1 both as a targeted vector and as an 

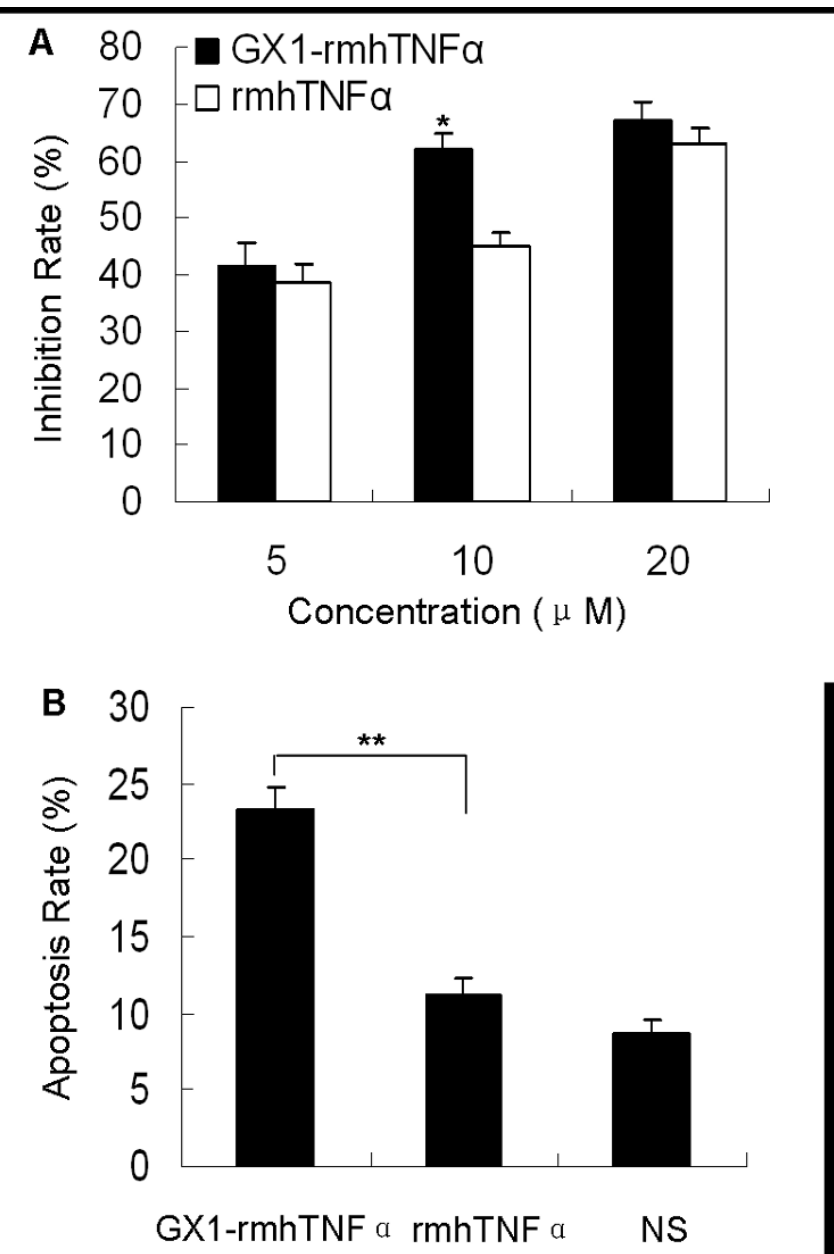

Figure 5

GXI-rmhTNF $\alpha$ inhibits co-HUVEC proliferation through induction of apoptosis. (A) GXI-rmhTNF $\alpha$ at $10 \mu \mathrm{M}$ more strongly inhibited co-HUVEC proliferation than rmhTNF $\alpha$. (B) GXI-rmhTNF $\alpha$ at I0 $\mu \mathrm{M}$ more strongly enhanced apoptosis of co-HUVEC than rmhTNF $\alpha$. The results are reported as mean $\pm S D$ of three independent experiments. Bars, SD. $* p<0.05,{ }^{* *} p<0.01$.

antiangiogenic agent in the diagnosis and treatment of human gastric cancer.

\section{Methods}

Reagents, antibodies and peptides

Growth factors and Evan's blue were purchased from Sigma (St. Louis, USA). M200 basal culture media and low serum growth supplement (LSGS) were from Cascade Biologics (USA). Anti-CD31 polyclonal antibody was from ABcam (USA) and anti-TNF monoclonal antibody was from Sigma Aldrich (Saint Louis, USA).

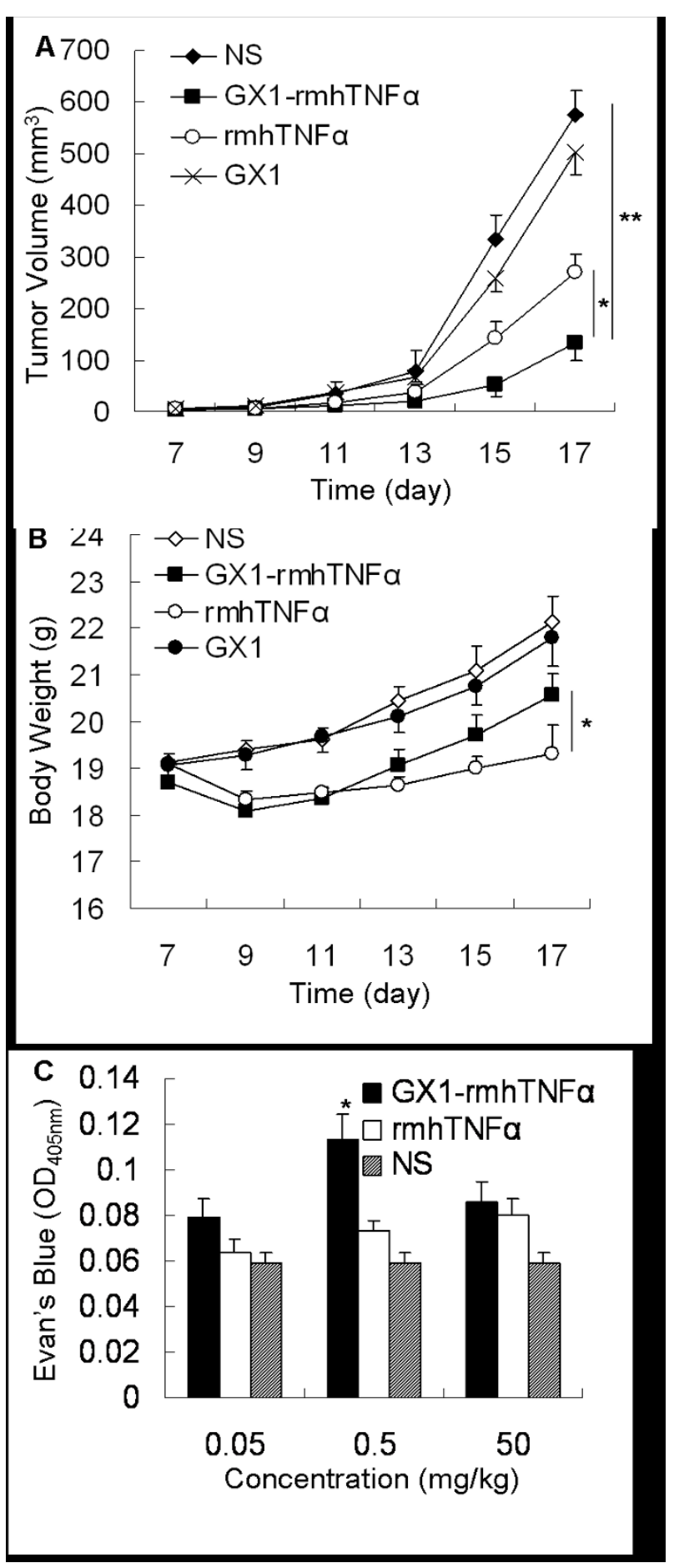

Figure 6

GXI-rmhTNF $\alpha$ inhibits tumor growth with decreased systemic toxicity by enhancing tumor vascular permeability. (A) GXI-rmhTNF $\alpha$ significantly delayed tumor growth. (B) GXI-rmhTNF $\alpha$ led to less weight loss than rmhTNF $\alpha$. (C) GXI-rmhTNF $\alpha$ induced a greater leakage of the dye in the tumor parenchyma than rmhTNF $\alpha$. Bars, SD. * $p<0.05,{ }^{* *} p<0.01$. 
GX1 peptide (CGNSNPKSC) was synthesized by GL Biochem (Shanghai) Ltd. A control peptide (Pep2) was created by randomly scrambling the amino acid sequence of GX1 while maintaining the disulfide bond to preserve the U-type structure (CNKSPSGNC). rmhTNF $\alpha$ was created by standard recombinant DNA techniques [11,31,32]. The GX1-rmhTNF $\alpha$ fusion protein was prepared as previously described [14].

\section{Cell cultures}

HUVEC (Cascade Biologics, USA) and the human gastric cancer cell line SGC7901 were cultured as described [28]. Tumor conditioned medium (TCM) was prepared by incubating SGC7901 cells in M200 (free of LSGS) $(\sim 1 \times$ $10^{6} / \mathrm{ml}$ ) for $24 \mathrm{~h}$. The medium was then removed, centrifuged $(2000 \times \mathrm{g}, 10 \mathrm{~min})$, filtered with a $0.22-\mu \mathrm{m}$ filter and diluted five times with M200 supplemented with LSGS. Tumor endothelial cells were generated by incubating HUVEC in TCM [29]. All cells were cultured at $37^{\circ} \mathrm{C}$ in a humidified chamber with $5 \% \mathrm{CO}_{2}$.

\section{MTT, FCM and western blot assays}

Proliferation of HUVEC and SGC7901 cells treated with various concentrations of tested agents was determined by MTT assay as described [33].

Apoptosis of co-HUVEC was detected by FCM analysis as described [34]. Cells were treated with GX1 $(50 \mu \mathrm{M})$ or GX1-rmhTNFa $(10 \mu \mathrm{M})$ for $48 \mathrm{~h}$. Pep2 $(50 \mu \mathrm{M})$, PBS or rmhTNF $\alpha(10 \mu \mathrm{M})$ were used as controls.

The expression level of caspase 3 was measured by western blot assay. The cultured cells were lyzed in modified RIPA buffer (0.05 M Tris-HCl, pH 7.4, 1\% NP-40, 0.25\% Nadeoxycholate, $0.15 \mathrm{M} \mathrm{NaCl}, 0.001 \mathrm{M} \mathrm{Na}_{3} \mathrm{VO}_{4}, 0.001 \mathrm{M}$ EDTA and $0.5 \%$ of protease inhibitor cocktail). The lysate was centrifuged at $10,000 \times \mathrm{g}, 4^{\circ} \mathrm{C}$ for 10 minute, and the supernatant was collected. Protein concentration was determined by the BCA protein assay (Pierce, Rockford, IL, USA). Proteins were separated by $10 \%$ SDS-PAGE and were transferred to PVDF membrane. western blot analysis was carried out using the following primary antibodies: anti-cleavage caspase 3 antibody (1:500; Abnova Corporation, Taipei, Taiwan) and anti- $\beta$-actin antibody (1:1000; Santa Cruz Biotechnology, Santa Cruz, CA, USA), followed by incubation with horseradish peroxidase (HRP) conjugated secondary antibody (Santa Cruz Biotechnology, Santa Cruz, CA, USA). The blots were visualized using enhanced chemiluminescence (ECL) kit (Amersham Pharmacia Biotech, Arlington Heights, IL, USA) according to manufacturer's instructions.

\section{Chorioallantoic Membrane (CAM) assay}

Fertilized White Leghorn chicken embryos were randomly divided into three groups with seven embryos per group, and collected on day 3 into sterile containers for subsequent incubation at $37^{\circ} \mathrm{C}, 5 \% \mathrm{CO}_{2}$ for 6 days. On day 9 , sterilized Whatman filter discs impregnated with $10 \mu \mathrm{l}$ $(20 \mu \mathrm{g})$ GX1 were placed on the CAM. Pep2 $(20 \mu \mathrm{g})$ and PBS were used as controls. On day 11, the CAM was cut, fixed by acetone and viewed under a microscope. Neovascularization around the disk was quantitated by determining the number of angiogenic vessels within the CAM around the disk.

\section{In vivo distribution of GXI- rmhTNF $\alpha$ by emission computed tomography (ECT)}

In vivo distribution of GX1-rmhTNFa in different organs of tumor-bearing nude mice was detected by enzymelinked immunosorbent assay (ELISA, see below) and ECT. A suspension of SGC7901 cells was prepared at $1 \times 10^{7}$ cells $/ \mathrm{ml}$. A total of $0.2 \mathrm{ml}$ of the cell suspension was implanted subcutaneously in the right upper flank of 4-6 week-old male nude BALB/c mice (animal centre of FMMU, Xi'an, Shannxi, China). Three weeks after injection, the mice were randomly divided into three groups with six mice per group, and treated with $0.25 \mathrm{mg} / \mathrm{kg}$ of GX1-rmhTNF $\alpha$ or rmhTNF $\alpha$, or NS through the tail vein. The agents were allowed to circulate for $0.5 \mathrm{~h}, 1 \mathrm{~h}$ and $2 \mathrm{~h}$ before blood samples were taken from the eye, and tumors and major organs were removed. Tissue samples were homogenized and sonicated at $4{ }^{\circ} \mathrm{C}$, followed by centrifugation for $10 \mathrm{~min}$ at $12,000 \times \mathrm{g}$. The supernatant was subjected to ELISA.

Simultaneously, GX1-rmhTNF $\alpha$ labeled with ${ }^{9}{ }^{9} \mathrm{Tc}^{\mathrm{m}} \mathrm{O}_{4}$. was used for dynamic imaging in biodistribution studies[28]. Anesthetized animals were injected intravenously with $200 \mu \mathrm{l}{ }^{99} \mathrm{Tc}^{\mathrm{m}}-\mathrm{GX} 1-\mathrm{rmhTNF} \alpha$ or ${ }^{9}{ }^{9} \mathrm{Tc}^{\mathrm{m}}$-rmhTNF $\alpha$ at 470-540 $\mu \mathrm{Ci}$ per mouse. Planar and single-photon emission tomography images with a low-energy collimator were obtained, with 200,000 counts acquired per image at the indicated timepoints. Time-dependent biodistribution studies were carried out by sacrificing mice at 2,8 , and $18 \mathrm{~h}$ after injection. Tissue samples were removed at the end of the test. The radioactivity was determined with a gamma counter and decay-corrected to the time of injection. Results were calculated as injected dose (ID) per gram of wet tissue weight (ID/g tissue), converted to percent. GX1-rmhTNF $\alpha /$ rmhTNF $\alpha$ radioactivity rates of various tissues were determined from the corresponding ID/g tissue values.

\section{ELISA, immunohistochemical staining and immunofluorescence staining}

The amount of GX1-rmhTNFa and rmhTNFa in tumor and other organs was quantified by ELISA kit (Department of Immunology, FMMU, Xi'an, Shannxi, China). The optical density at $470 \mathrm{~nm}$ was measured with a microplate reader (Bio-Rad Laboratories, Hercules, CA). 
Immunohistochemical staining was performed as described [35] using anti-TNF monoclonal antibody and anti-CD31 polyclonal antibody. For immunofluorescence, tumor sections were incubated with diluted antiTNF monoclonal antibodies and anti-CD31 polyclonal antibodies at $4{ }^{\circ} \mathrm{C}$ overnight, and then treated with rhodamine-conjugated goat anti-mouse IgG and fluorescein isothiocyanate-conjugated goat anti-rabbit IgG at 1:200 for $1 \mathrm{~h}$ at room temperature. Sections were analyzed by fluorescence microscopy.

\section{Evan's blue assay}

Twenty days after subcutaneous injection of SGC7901 cells, nude mice were intravenously treated with GX1rmhTNF $\alpha$, with rmhTNF $\alpha$ and NS as controls. Two hours later, the mice were intravenously injected with $0.1 \mathrm{ml}$ Evan's blue (Sigma, St. Louis, MO; $12.5 \mathrm{mg} / \mathrm{ml}$ ). After 5 min, the animals were sacrificed and the tumors were excised. Each tumor was weighed, homogenized, resuspended in cold PBS containing $1 \%$ Triton X-100 (1 ml/g), and incubated for $1 \mathrm{~h}$ on ice. The suspension was centrifuged $\left(14,000 \times \mathrm{g}, 4^{\circ} \mathrm{C}, 15 \mathrm{~min}\right)$, and the supernatant mixed with trichloroacetic acid $(10 \%, \mathrm{v} / \mathrm{v})$. The product was centrifuged again $\left(14,000 \times \mathrm{g}, 4^{\circ} \mathrm{C}, 15 \mathrm{~min}\right)$ and the absorbance at $405 \mathrm{~nm}$ of the supernatant was measured using a spectrophotometer.

\section{In vivo tumor formation assay}

Seven days after injection of SGC7901 cells as described above, nude mice were randomly divided into groups of seven mice and treated with the indicated reagents on alternate days. Tumor development was observed by sequential caliper measurements of length (L) and width (W). Tumor volume was calculated by the formula $\mathrm{L} \times$ $\mathrm{W}^{2} / 2$. After 20 days, the mice were killed and the tumors were removed and weighed. All studies were performed according to internationally recognized guidelines for animal care.

\section{Statistical analysis}

Each experiment was repeated at least three times. Numerical data are presented as mean \pm standard deviation (SD). The difference between means was analyzed by ANOVA. All statistical analyses were performed using SPSS11.0 software (Chicago, IL). Differences were considered statistically significant when $p<0.05$.

\section{Authors' contributions}

BC, SSC designed, carried out the experiments, analyzed data and drafted the manuscript. XLH labeled GX1 with ${ }^{9} \mathrm{~T}^{\mathrm{m}} \mathrm{O}_{4}-$, performed the ECT imaging and commented on the manuscript. YW performed Evan's blue assay and commented on the manuscript. WQD performed FCM assay and corrected the final manuscript. LW performed ELISA and commented on the manuscript. XW, JL, YQZ,
DMF supervised the project and commented on the manuscript. KCW obtained funding, supervised the project and corrected final manuscript. All authors read and approved the final manuscript.

\section{Acknowledgements}

This work was supported by grants from the National Bio-Tech 86-3 Program (No. 2006AA022103), Medical and Healthcare Project of PLA (No. 06G087), National Key Project of Basic Research (No. 2004CB5 I8702) and National Foundation of Natural Science, China (No. 30130260, No. 30024002 and No. 30873005).

\section{References}

I. Folkman J: Tumor angiogenesis: therapeutic implications. $N$ Engl J Med I97I, 285: I I82-II86.

2. Cai W, Chen X: Multimodality molecular imaging of tumor angiogenesis. J Nucl Med 2008, 49(Suppl 2): I I3S-128S.

3. Corti A, Curnis F, Arap W, Pasqualini R: The neovasculature homing motif NGR: more than meets the eye. Blood 2008, I I 2:2628-2635.

4. St Croix B, Rago C, Velculescu V, Traverso G, Romans KE, Montgomery $E$, Lal A, Riggins G], Lengauer C, Vogelstein B, Kinzler KW: Genes expressed in human tumor endothelium. Science 2000, 289: I| $197-1202$.

5. Folkman J: Angiogenesis and apoptosis. Semin Cancer Biol 2003, 13:159-167.

6. Denekamp J: Vascular attack as a therapeutic strategy for cancer. Cancer Metastasis Rev 1990, 9:267-282.

7. Hajitou A, Pasqualini R, Arap W: Vascular targeting: recent advances and therapeutic perspectives. Trends Cardiovasc Med 2006, 16:80-88

8. Arap W, Kolonin MG, Trepel M, Lahdenranta J, Cardo-Vila M, Giordano RJ, Mintz PJ, Ardelt PU, Yao VJ, Vidal Cl, Chen L, Flamm A, Valtanen H, Weavind LM, Hicks ME, Pollock RE, Botz GH, Bucana CD, Koivunen E, Cahill D, Troncoso P, Baggerly KA, Pentz RD, Do KA, Logothetis CJ, Pasqualini R: Steps toward mapping the human vasculature by phage display. Nat Med 2002, 8: I 2 I- 127.

9. Zhi M, Wu KC, Dong L, Hao ZM, Deng TZ, Hong L, Liang SH, Zhao PT, Qiao TD, Wang Y, Xu X, Fan DM: Characterization of a specific phage-displayed Peptide binding to vasculature of human gastric cancer. Cancer Biol Ther 2004, 3: I 232-I235.

10. Han Y, Hong L, Wu K, Cao S, He L, Fan D: Expression of vascularbinding peptide CGNSNPKSC in gastric cancer and the identification of its possible receptor. Modern Oncology 2007, I5:458-460.

II. Wang H, Yan Z, Shi J, Han W, Zhang Y: Expression, purification, and characterization of a neovasculature targeted rmhTNFalpha in Escherichia coli. Protein Expr Purif 2006, 45:60-65.

12. Zhang YQ, Zhao N, Li B, Liu L, Wang ZL, Zhu BE, Yan ZL, Su CZ: Preparation of a novel recombinant human tumor necrosis factor- $\alpha$ by gene engineering technology. Chin J Cell Mol Immunol 2002, I 8:402-405.

13. Khodarev NN, Yu J, Labay E, Darga T, Brown CK, Mauceri HJ, Yassari R, Gupta N, Weichselbaum RR: Tumour-endothelium interactions in co-culture: coordinated changes of gene expression profiles and phenotypic properties of endothelial cells. J Cell Sci 2003, I16:1013-1022.

14. Cao S, Wu K, Yan Z, Wan Y, Han Y, Zhao L, Fan D: Cloning, expression and identification of recombinant fusion protein GXI- rmhTNF $\alpha$. Chin I Cell Mol Immunol 2006, 22:360-362.

15. Lejeune F, Lienard D, Eggermont A, Schraffordt Koops H, Rosenkaimer F, Gerain J, Klaase J, Kroon B, Vanderveken J, Schmitz P: Rationale for using TNF alpha and chemotherapy in regional therapy of melanoma. J Cell Biochem 1994, 56:52-61.

16. Shaked Y, Henke E, Roodhart JM, Mancuso P, Langenberg MH, Colleoni M, Daenen LG, Man S, Xu P, Emmenegger U, Tang T, Zhu Z, Witte L, Strieter RM, Bertolini F, Voest EE, Benezra R, Kerbel RS: Rapid chemotherapy-induced acute endothelial progenitor cell mobilization: implications for antiangiogenic drugs as chemosensitizing agents. Cancer Cell 2008, 14:263-273.

17. Dy GK, Adjei AA: Systemic cancer therapy: evolution over the last 60 years. Cancer 2008, II 3:1857-1887. 
18. Field K, Michael M, Leong T: Locally advanced and metastatic gastric cancer: current management and new treatment developments. Drugs 2008, 68:299-317.

19. Ellis LM, Hicklin DJ: VEGF-targeted therapy: mechanisms of anti-tumour activity. Nat Rev Cancer 2008, 8:579-59l.

20. Marshall J: Clinical implications of the mechanism of epidermal growth factor receptor inhibitors. Cancer 2006, 107:1207-1218.

21. Zacher AN 3rd, Stock CA, Golden JW 2nd, Smith GP: A new filamentous phage cloning vector: fd-tet. Gene 1980, 9:I27-I40.

22. Porkka K, Laakkonen P, Hoffman JA, Bernasconi M, Ruoslahti E: A fragment of the HMGN2 protein homes to the nuclei of tumor cells and tumor endothelial cells in vivo. Proc Natl Acad Sci USA 2002, 99:7444-7449.

23. Pasqualini R, Koivunen E, Ruoslahti E: Alpha v integrins as receptors for tumor targeting by circulating ligands. Nat Biotechnol 1997, I 5:542-546.

24. Laakkonen $\mathrm{P}$, Akerman $\mathrm{ME}$, Biliran $\mathrm{H}$, Yang $\mathrm{M}$, Ferrer $\mathrm{F}$, Karpanen $\mathrm{T}$, Hoffman RM, Ruoslahti E: Antitumor activity of a homing peptide that targets tumor lymphatics and tumor cells. Proc Natl Acad Sci USA 2004, 101:9381-9386.

25. Gehlsen KR, Argraves WS, Pierschbacher MD, Ruoslahti E: Inhibition of in vitro tumor cell invasion by Arg-Gly-Asp-containing synthetic peptides. J Cell Biol 1988, I 06:925-930.

26. Allen TM: Ligand-targeted therapeutics in anticancer therapy. Nat Rev Cancer 2002, 2:750-763.

27. Rowlinson-Busza G, Epenetos AA: Targeted delivery of biologic and other antineoplastic agents. Curr Opin Oncol 1992, 4: || $42-|| 48$.

28. Hui X, Han Y, Liang S, Liu Z, Liu J, Hong L, Zhao L, He L, Cao S, Chen B, Yan K, Jin B, Chai N, Wang J, Wu K, Fan D: Specific targeting of the vasculature of gastric cancer by a new tumor-homing peptide CGNSNPKSC. J Control Release 2008, I 3 I:86-93.

29. Tanaka $Y$, Abe M, Hiasa M, Oda A, Amou $H$, Nakano A, Takeuchi $K$, Kitazoe K, Kido S, Inoue D, Moriyama K, Hashimoto T, Ozaki S, Matsumoto T: Myeloma cell-osteoclast interaction enhances angiogenesis together with bone resorption: a role for vascular endothelial cell growth factor and osteopontin. Clin Cancer Res 2007, I 3:816-823.

30. Eliceiri BP, Cheresh DA: The role of alphav integrins during angiogenesis: insights into potential mechanisms of action and clinical development. | Clin Invest 1999, I 03: | 227- I 230.

31. Lowenstein PR: Clinical trials in gene therapy: ethics of informed consent and the future of experimental medicine. Curr Opin Mol Ther 2008, 10:428-430.

32. Han W, Zhang Y, Yan Z: Construction of a new tumor necrosis factor fusion-protein expression vector for high-level expression of heterologous genes in Escherichia coli. Biotechnol Appl Biochem 2003, 37:109-II3.

33. Yamaue H, Tanimura H, Noguchi K, Hotta T, Tani M, Tsunoda T, Iwahashi M, Tamai M, Iwakura S: Chemosensitivity testing of fresh human gastric cancer with highly purified tumour cells using the MTT assay. Br J Cancer 1992, 66:794-799.

34. Milner AE, Levens JM, Gregory CD: Flow cytometric methods of analyzing apoptotic cells. Methods Mol Biol 1998, 80:347-354.

35. Wang L, Wei D, Huang S, Peng Z, Le X, Wu TT, Yao J, Ajani J, Xie K: Transcription factor $\mathrm{Sp} \mathrm{I}$ expression is a significant predictor of survival in human gastric cancer. Clin Cancer Res 2003, 9:637|-6380.
Publish with Bio Med Central and every scientist can read your work free of charge

"BioMed Central will be the most significant development for disseminating the results of biomedical research in our lifetime. "

Sir Paul Nurse, Cancer Research UK

Your research papers will be:

- available free of charge to the entire biomedical community

- peer reviewed and published immediately upon acceptance

- cited in PubMed and archived on PubMed Central

- yours - you keep the copyright
BioMedcentral 